\title{
Sistem Informasi Geografis Letak Industri Kecil dan Menengah berbasis android di Provinsi Gorontalo
}

\author{
Bahtiar Senung ${ }^{1}$, Syaifuddin ${ }^{2}$ \\ 11e-mail: bahtiarsenung@gmail.com, ${ }^{2,}$ syaifuddinlily@gmail.com, \\ ${ }^{12}$ Sistem Informasi, STMIK Ichsan Gorontalo,
}

\begin{abstract}
Small and Medium Industry is the program and policy of the Local Government of Gorontalo Province to achieve development goals in the field of economy, especially related to the development efforts of small and medium industry sectors (IKM). The Cooperative, Industrial and Trade Office of Gorontalo Province desperately needs accurate data information for the search and determination of small and medium industry locations and also in terms of regional development planning and spatial arrangement, but in reality, to obtain data and information on the spread of Small and Medium Industry spread almost throughout Gorontalo province is very difficult, this is due to the absence of an information system that handles this. The Government's current geographic information system cannot access the search and location of the Small and Medium Industry. The expansion of the area that occurs in Gorontalo Province from 6 districts, the addition of fickle regions and addresses can confuse and make it difficult for local people or tourists outside Gorontalo province to get information about the small and medium industry in Gorontalo Province. The lack of information to the public about the location of Small and Medium Industry locations in Gorontalo province can make it difficult to conduct cooperation that can drive the regional economy. Information search and access user information and communication technology through high mobility media such as smartphones. Today's thriving smartphones are smartphones with android operating systems. Android smartphone besides having high mobility, also has very useful features such as google maps and GPS. Google maps and GPS features can collaborate in an android app program creation. Application program creation is designed using android and PHP programming languages collaborated with MySQL databases as data container media. The research aims to make it easier for people to get information about small and medium-sized industries and information about small and medium-sized industries. The availability of information can be a bridge for the community to cooperate and drive the regional economy.
\end{abstract}

Keywords — IKM, Small to medium industry, Geographic information systems, Android.

Intisari- Industri Kecil dan Menengah merupakan program dan kebijakan Pemerintah Daerah Provinsi Gorontalo dalam rangka mencapai sasaran pembangunan di bidang ekonomi, khususnya yang terkait dengan upaya pengembangan sektor industri kecil dan menengah (IKM). Dinas Koperasi, Perindustrian dan Perdagangan Provinsi Gorontalo sangat memerlukan informasi data yang akurat untuk pencarian dan penentuan lokasi Industri Kecil dan Menengah dan juga dalam hal perencanaan pembangunan daerah dan penataan ruang, namun pada kenyataannya untuk memperoleh data dan informasi mengenai penyebaran Industri Kecil dan Menengah yang tersebar hampir diseluruh wilayah Provinsi Gorontalo sangat sulit, hal ini disebabkan belum adanya sistem informasi yang menangani hal tersebut. Sistem informasi geografis yang ada pada Pemerintah saat ini belum dapat mengakses pencarian dan penentuan lokasi Industri Kecil dan Menengah. Pemekaran wilayah yang terjadi di Provinsi Gorontalo dari 6 Kabupaten, penambahan wilayah dan alamat yang berubah-ubah dapat membingungkan dan mempersulit masyarakat atau wisatawan lokal yang berada diluar daerah Provinsi Gorontalo dalam mendapatkan informasi tentang Industri Kecil dan Menengah yang ada di Provinsi Gorontalo. Kurangnya informasi kepada masyarakat tentang letak lokasi Industri Kecil dan Menengah di provinsi Gorontalo sehingga dapat mempersulit dalam melakukan kerjasama yang dapat menggerakkan perekonomian daerah. Pencarian dan pengaksesan informasi menggunakan teknologi informasi dan komunikasi melalui media yang punya mobilitas tinggi seperti smartphone. Smartphone yang berkembang dimasa sekarang ialah smartphone bersistem operasi android. Smartphone android disamping punya mobilitas tinggi, juga memiliki fitur-fitur yang sangat berguna seperti google maps dan GPS. Fitur Google maps dan GPS dapat dikolaborasikan dalam sebuah pembuatan program aplikasi android. Pembuatan program aplikasi dirancang menggunakan Bahasa pemrograman android dan php yang dikolaborasikan dengan database MySQL sebagai media penampung data. Penelitian bertujuan untul Mempermudah masyarakat dalam mendapatkan informasi letak lokasi Industri Kecil dan Menengah serta informasi tentang Industri Kecil dan Menengah. Ketersediaan informasi dapat menjadi jembatan bagi masyarakat untuk bekerjasama dan menggerakkan perekonomian daerah.

Kata Kunci- IKM, Industri kecil menengah, Sistem Informasi Geografis, Android

\section{PENDAHULUAN}

Perkembangan pemanfaatan data spasial dalam dekade belakangan ini meningkat dengan sangat drastis. Hal ini berkaitan dengan meluasnya pemanfaatan Sistem Informasi Geografis (SIG) dan perkembangan teknologi dalam memperoleh, merekam dan mengumpulkan data yang bersifat keruangan (spasial). Teknologi tinggi seperti Global Positioning System (GPS), remote sensing dan total station, telah membuat perekaman data spasial digital relatif lebih cepat dan mudah. Kemampuan 
penyimpanan yang semakin besar, kapasitas transfer data yang semakin meningkat, dan kecepatan proses data yang semakin cepat menjadikan data spasial merupakan bagian yang tidak terlepaskan dari perkembangan teknologi informasi.

Salah satu fasilitas yang diberikan oleh Smartphone Android pada saat ini adalah memberikan informasi dan jarak suatu tempat melalui teknologi Geographic Information System (GIS) dengan layanan Location Based Service (LBS). Akan ditampilkan sebuah peta lengkap dengan koordinat longitude maupun koordinat latitude. Industri Kecil dan Menengah merupakan program dan kebijakan Pemerintah Daerah Provinsi Gorontalo dalam rangka mencapai sasaran pembangunan di bidang ekonomi, khususnya yang terkait dengan upaya pengembangan sektor industri kecil dan menengah (IKM).

Sistem Informasi Geografis merupakan salah satu instrumen Informasi Teknologi yang sangat penting dalam membantu aktivitas pemerintahan. Dengan Sistem Informasi Geografis kondisi alam atau tata ruang bisa diketahui secara pasti. Momentum ini sudah saatnya digunakan untuk pengembangan wilayah oleh Provinsi Gorontalo di era otonomi daerah sekarang ini. Salah satu kelemahan pemerintah daerah kita sekarang ini adalah kurangnya kemampuan diri dalam memanfaatkan teknologi secara maksimal. Misalnya dengan dipilihnya suatu lokasi dalam peta maka akan ditampilkan informasi yang berhubungan dengan lokasi yang diinginkan atau sebaliknya dengan memilih informasi yang tersedia maka lokasi dari informasi tersebut akan ditampilkan dalam peta. Sistem Informasi Geografis (SIG) dapat dipilih jadi pemecahan masalah disebabkan oleh pemetaan Industri Kecil dan Menengah serta faktor pendukungnya dapat ditampilkan secara jelas dan akurat sehingga diharapkan dengan adanya sistem ini dapat lebih meningkatkan dan menjaga tingkat industri kecil dan menengah, khususnya di Provinsi Gorontalo.

Industri Kecil dan Menengah merupakan program dan kebijakan Pemerintah Daerah Provinsi Gorontalo dalam rangka mencapai sasaran pembangunan di bidang ekonomi, khususnya yang terkait dengan upaya pengembangan sektor industri kecil dan menengah (IKM). Dari sejumlah komoditas yang menopang kontribusi produk industri pengolahan berskala kecil dan menengah di seputar kawasan kabupaten ini, terdapat beberapa jenis produk andalan yang dikaji menurut aspek daya serap tenaga kerja, nilai investasi, jumlah unit usaha, kapasitas produksi dan nilainya per-tahun. Berikut adalah daftar Industri Kecil Menengah (IKM) di Provinsi Gorontalo :

Tabel 1.1 Daftar IKM Provinsi Gorontalo tahun 2015

\begin{tabular}{|c|c|c|c|c|c|}
\hline No & Nama Kabupaten & Jenis Produksi & $\begin{array}{l}\text { Jumlah } \\
\text { Kecamatan }\end{array}$ & $\begin{array}{l}\text { Jumlah } \\
\text { Kelurahan/Desa }\end{array}$ & $\begin{array}{l}\text { Jumlah } \\
\text { IKM }\end{array}$ \\
\hline \multirow{6}{*}{1} & \multirow{6}{*}{ Kab. Boalemo } & Abon Ikan Tuna & 2 & 2 & 2 \\
\hline & & Anyaman Tikar & 6 & 20 & 46 \\
\hline & & Batu Bata & 5 & 26 & 91 \\
\hline & & Gula Aren & 4 & 5 & 19 \\
\hline & & Meubel Kayu & 5 & 22 & 54 \\
\hline & & $\begin{array}{l}\text { Perabot Rumah } \\
\text { Tangga }\end{array}$ & 2 & 12 & 25 \\
\hline \multirow{7}{*}{2} & \multirow{7}{*}{$\begin{array}{l}\text { Kab. } \\
\text { Bolango }\end{array}$} & $\begin{array}{l}\text { Industri Gula } \\
\text { Merah }\end{array}$ & 9 & 9 & 365 \\
\hline & & $\begin{array}{l}\text { Industri Kerupuk } \\
\text { dan sejenisnya }\end{array}$ & 1 & 1 & 13 \\
\hline & & $\begin{array}{l}\text { Industri Minyak } \\
\text { Goreng Kelapa }\end{array}$ & 6 & 6 & 92 \\
\hline & & $\begin{array}{l}\text { Industri Produk } \\
\text { Roti dan Kue }\end{array}$ & 9 & 9 & 143 \\
\hline & & $\begin{array}{l}\text { Industri Anyaman } \\
\text { dari tanaman }\end{array}$ & 5 & 5 & 100 \\
\hline & & $\begin{array}{l}\text { Industri } \\
\text { Sulaman/Bordir }\end{array}$ & 7 & 7 & 205 \\
\hline & & $\begin{array}{l}\text { Industri Furniture } \\
\text { Dari Kayu }\end{array}$ & 5 & 5 & 69 \\
\hline \multirow{2}{*}{3} & \multirow{2}{*}{ Kab. Pohuwato } & $\begin{array}{ll}\text { Industri } & \text { Kue } \\
\text { Basah } & \\
\end{array}$ & 13 & 82 & 533 \\
\hline & & $\begin{array}{l}\text { Industri Furniture } \\
\text { Dari Kayu }\end{array}$ & 13 & 86 & 310 \\
\hline
\end{tabular}




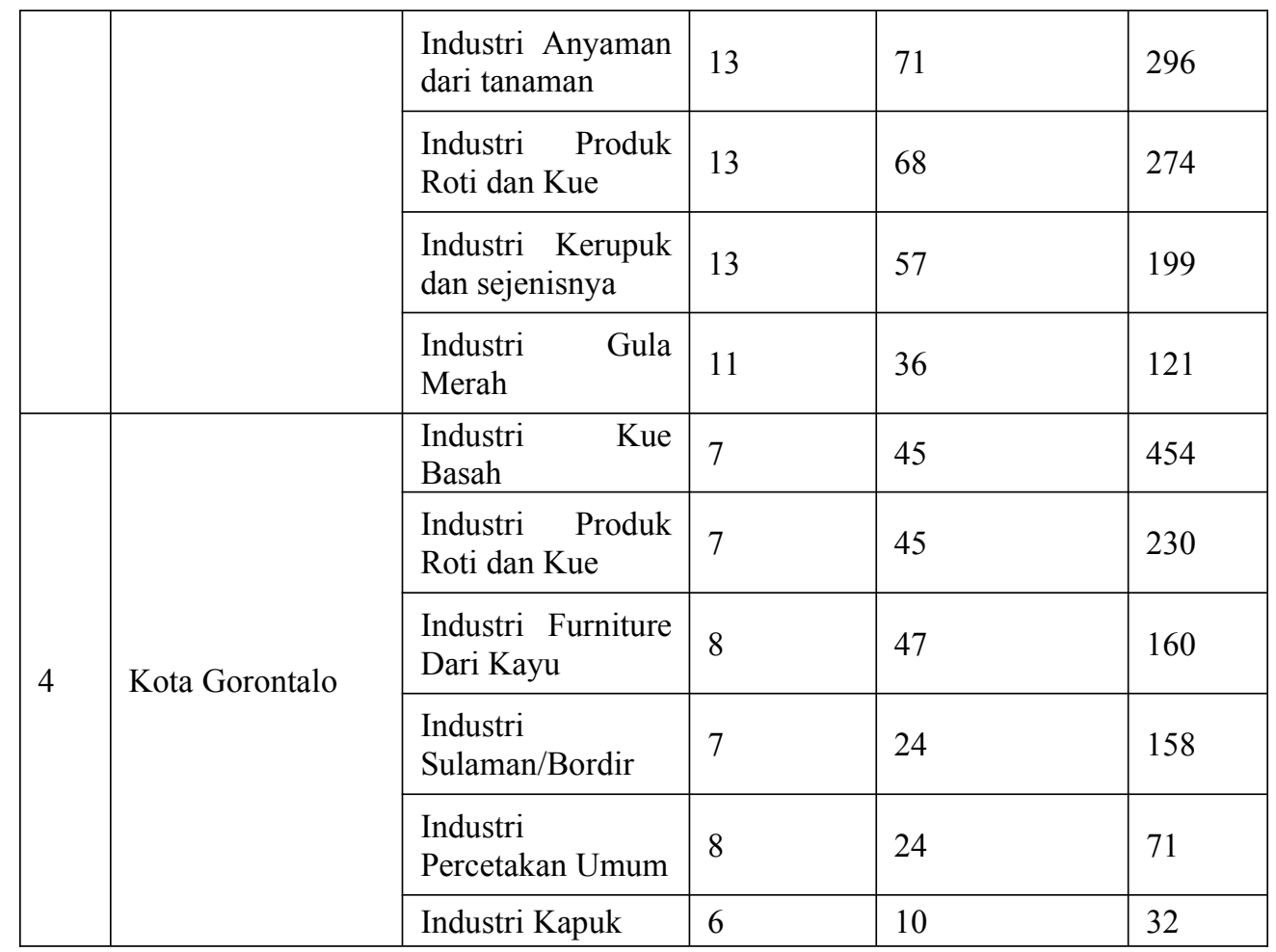

Sumber : Dinas Koperasi, Perindustrian dan Perdagangan Provinsi Gorontalo

Dengan adanya penyebaran Industri Kecil dan Menengah yang ada di wilayah Provinsi Gorontalo, maka pemerintah Provinsi Gorontalo membutuhkan suatu pengelolaan data untuk penyajian informasi. Informasi penyebaran Industri Kecil dan Menengah merupakan hasil pengolahan data yang saling berkaitan melalui proses analisis data, sehingga dapat dihasilkan informasi yang akan menjadi faktor penting/pedoman dalam hal perencanaan pemetaan Industri Kecil dan Menengah yang berada di wilayah Provinsi Gorontalo. Penyajian informasi yang baik diharapkan dapat membantu memenuhi kebutuhan informasi pada masyarakat sehingga proses perencanaan pembangunan dan penataan ruang yang ada di Provinsi Gorontalo bisa berjalan dengan baik.

Dinas Koperasi, Perindustrian dan Perdagangan Provinsi Gorontalo sangat memerlukan informasi data yang akurat untuk pencarian dan penentuan lokasi Industri Kecil dan Menengah dan juga dalam hal perencanaan pembangunan daerah dan penataan ruang, namun pada kenyataannya untuk memperoleh data dan informasi mengenai penyebaran Industri Kecil dan Menengah yang tersebar hampir diseluruh wilayah Provinsi Gorontalo sangat sulit, hal ini disebabkan belum adanya sistem informasi yang menangani hal tersebut.

Sistem informasi geografis yang ada pada Pemerintah saat ini belum dapat mengakses pencarian dan penentuan lokasi Industri Kecil dan Menengah. Pemekaran wilayah yang terjadi di Provinsi Gorontalo dari 6 Kabupaten, penambahan wilayah dan alamat yang berubah-ubah dapat membingungkan dan mempersulit masyarakat atau wisatawan lokal yang berada diluar daerah Provinsi Gorontalo dalam mendapatkan informasi tentang Industri Kecil dan Menengah yang ada di Provinsi Gorontalo.

\section{TUJUAN PENELITIAN}

Mempermudah masyarakat untuk mendapatkan informasi letak lokasi Industri Kecil dan Menengah serta informasi tentang Industri Kecil dan Menengah. Ketersediaan informasi dapat menjadi jembatan bagi masyarakat untuk bekerjasama dan menggerakkan perekonomian daerah.

\section{METODE PENELITIAN}

\section{Metode Penelitian}

Adapun metode yang digunakan dalam analisis sistem adalah metode rekayasa perangkat lunak dengan model prototipe (Prototyping Model). Model ini bertujuan untuk membuat ptototipe dari perangkat lunak yang akan dibuat. Dalam [9], menyatakan bahwa sering pelanggan (costumer) membayangkan kumpulan kebutuhan yang di inginkan tapi tidak terspesifikasikan secara detail dari segi masukan (input), proses maupun keluaran (output). Model prototipe dapat digunakan 
untuk memastikan efisiensi algoritma dan kemampuan penyesuaian dari Sistem Operasi dan bentuk-bentuk yang harus dilakukan terhadap antarmuka suatu sistem. Model Prototipe dapat dilihat pada gambar dibawah ini.

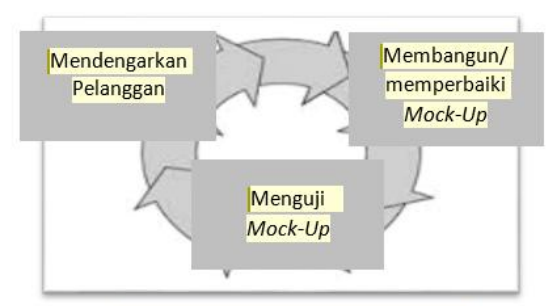

Gambar. Ilustrasi Model Prototipe

\section{Objek Penelitian}

Objek dari penelitian ini adalah Dinas Koperasi, Perindustrian dan Perdagangan Provinsi Gorontalo. Dinas Koperasi ,Perindustrian dan Perdagangan Provinsi yang membawahi semua indusri kecil dan menengah yang ada di Provinsi Gorontalo

\section{Tahapan Analisis Pembuatan Sistem}

Dalam pembuatan sistem dengan menggunakan metode prototipe ini yaitu :

1. Pengumpulan data dan menganalisis kebutuhan

Didalam pembuatan system menggunakan metode prototipe dibutuhkan data-data pendukung yang diperole dengan pengumpulan data yang relevan dan sesuai dengan kebutuhan sistem yang akan dibangun. Metode-metode pengumpulan data yang di gunakan yaitu :

a. Metode observasi.

Metode observasi yang dilakukan pada penelitian ini yaitu peninjauan lansung ke tempat industri kecil dan menengah yang ada di provinsi gorontalo untuk pengambilan data berupa gambar, informasi dan titik koordinat..

b. Metode wawancara

Wawancara dilakukan untuk mengetahui informasi-informasi lebih mendalam langsung dari dinas lingkungan hidup sehingga peneliti dapat mengetahui apa saja yang dibutuhkan untuk pengembangan sistem yang akan dibuat dan disesuaikan dengan kebutuhan.

C. Metode dokumentasi

Dokumentasi merupakan pengumpulan data dimana dalam penelitiaan ini data yang digunakan yaitu data berupa gambar dan koordinat dari industry kecil dan menengah.

2. Perancangan cepat.

3. Membangun sebuah prototipe

4. Evaluasi oleh konsumen atas prototipe

5. Perubahan rancangan dan prototipe

6. Apabila prototipe yang dibangun tidak sesuai denan kebutuhan maka ulangi langkah 5, dan

7. Apabila sudah sesuai dengan kebutuhan terhadap prototipe yang di bangun, maka pembuatan dan pengembangan produk segera dapat dimulai..

\section{ANALISIS DAN DESAIN SISTEM}

\section{Analisa Sistem yang diusulkan}

Sistem yang diusulkan digambarkan dengan usecase diagram di bawah ini. 


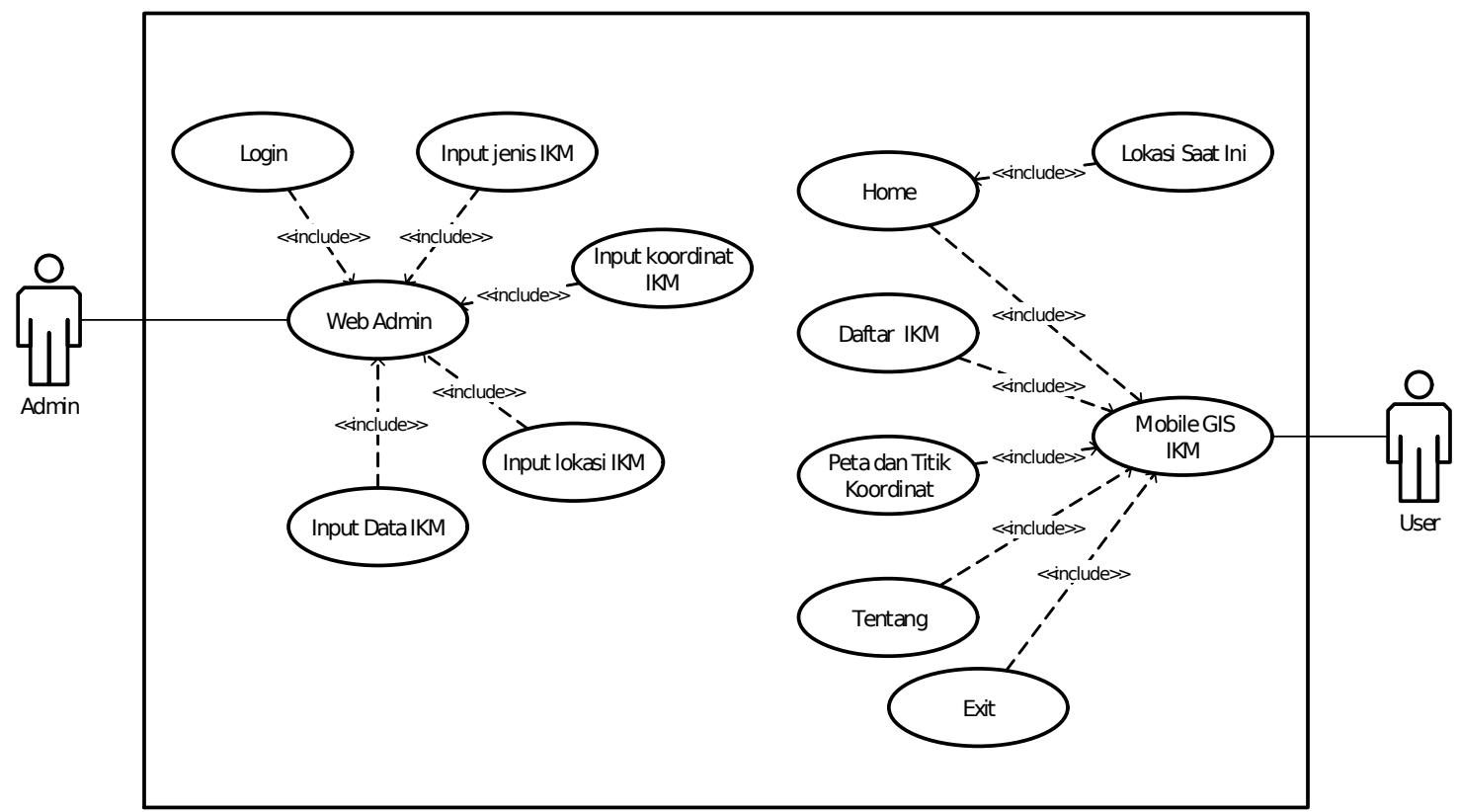

Gambar 4.1 Sistem yang diusulkan

\section{Analisis Sistem}

Sistem yang dibuat memiliki 2 aktor yaitu pegawai dinas perindustrian dan perdagangan provinsi selaku admin dan masyarakat selaku user. admin melakukan pengelolaan data lokasi UKM. Admin juga mengelola data informasi serta mengelola data pengaduan dari masyarakat. masyarakat dapat mencari lokasi UKM serta melihat rute menuju ke lokasi UKM tersebut. System yang dirancang juga memungkinkan masyarakat menyampaikan pengaduan dan juga melihat informasi terkait dengan dinas perindustrian dan perdagangan provinsi. Sistem yang dirancang dilengkapi fitur bantuan apabila masyarakat mengalami kesulitan dalam mengoperasikannya. Berikut adalah gambaran system yang telah dirancang.

\section{Perancangan Sistem}

Perancangan Database

Database yang dirancang untuk pembuatan aplikasi sebanyak 4 tabel yaitu UKM, informasi, pengaduan dan admin. Berikut gambar rancangan database yang telah dibuat.

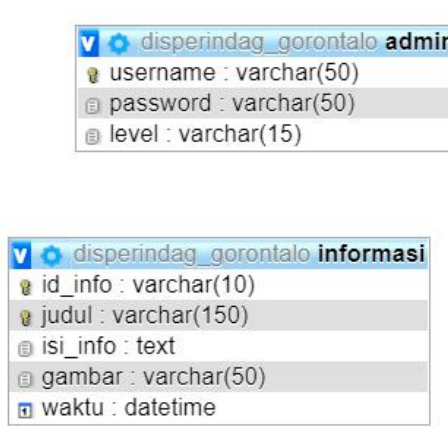

\begin{tabular}{|c|}
\hline Vo disperindag_gorontalc \\
\hline e id_ukm : varchar(5) \\
\hline e nama_ukm : varchar $(60)$ \\
\hline (1) nama_pemilik : varchar(50) \\
\hline (3) alamat : varchar(100) \\
\hline (e) kota_kab : varchar(40) \\
\hline (1) bentuk_usaha : varchar(35) \\
\hline (1) komoditi : varchar(55) \\
\hline (e) nama_produk : varchar(60) \\
\hline (e) latitude : varchar(20) \\
\hline (e) longitude : varchar(20) \\
\hline (e) gambar : varchar(50) \\
\hline
\end{tabular}

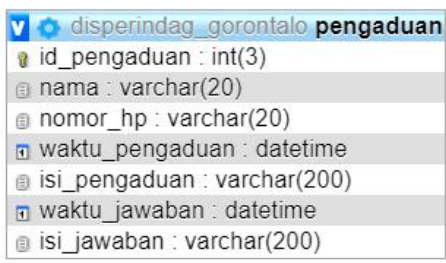

Gambar 4.2 Perancangan Database

\section{Perancangan Interface}

Pada tahap perancangan interface berupa tampilan geografis UKM, daftar UKM dan detail informsai UKM. Berikut gambar dari masing-masing interface. 


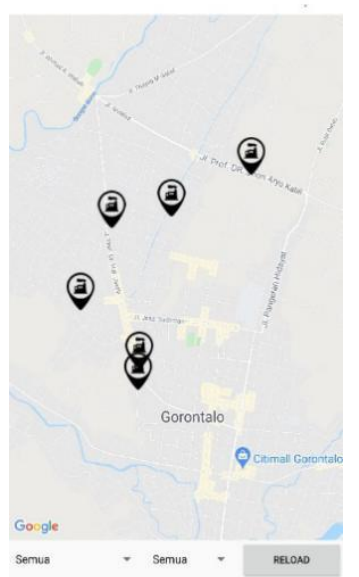

Gambar 4.3 Tampilan Geografis UKM

Tampilan Geografis UKM berfungsi untuk melihat lokasi UKM yang tersebar di provinsi Gorontalo dalam bentuk grafis.

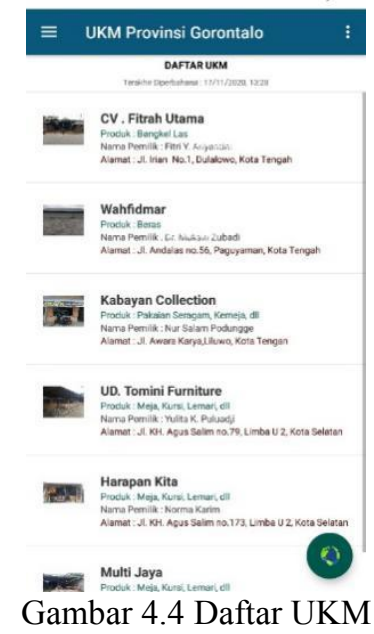

Daftar UKM berfungsi untuk menampilkan secara keseluruhan UKM yang ada di provinsi gorontalo.

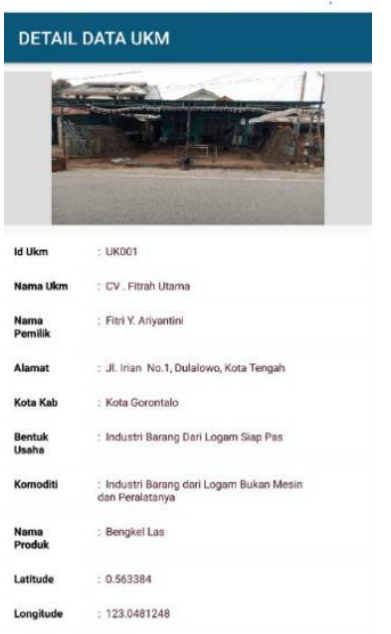

Gambar 4.5 Detail Informasi UKM

Detail Informasi UKM berfungsi untuk menampilkan detail informasi tentang UKM yang dipilih. 


\section{KESIMPULAN}

Sistem Informasi Geografis ini menjadi salah satu instrumen informasi teknologi yang sangat penting dalam membantu aktivitas pemerintahan. Momentum ini sudah saatnya digunakan untuk pengembangan wilayah oleh Provinsi Gorontalo di era otonomi daerah. Salah satu kelemahan pemerintah daerah kita sekarang ini adalah kurangnya kemampuan diri dalam memanfaatkan teknologi secara maksimal. Dengan dipilihnya suatu lokasi dalam peta maka akan ditampilkan informasi yang berhubungan dengan lokasi yang diinginkan atau sebaliknya dengan memilih informasi yang tersedia maka lokasi dari informasi tersebut akan ditampilkan dalam peta. Sistem Informasi Geografis (SIG) dipilih jadi pemecahan masalah disebabkan oleh pemetaan Industri Kecil dan Menengah serta faktor pendukungnya dapat ditampilkan secara jelas dan akurat sehingga diharapkan dengan adanya sistem ini dapat lebih meningkatkan dan menjaga tingkat industri kecil dan menengah, khususnya di Provinsi Gorontalo. Hasil penelitian yang dilakukan dapat digunakan untuk membantu dinas terkait dalam melaksanakan tugas.

\section{SARAN}

Pengembangan aplikasi system informasi geografis ini dapat dilakukan, aplikasi ini masih dalam tahap pengembangan sehingga peneliti selanjutnya disarankan menambahkan metode yang dapat menentukan jarak terdekat atau terjauh secara akurat atau fitur yang memungkinkan user dapat mengupdate tanpa harus melaporkan ke Admin.

\section{REFERENSI}

[1] Agrarian, R. Putra, Suprayogi, Andri, dan Yuwono, B. Darmo, 2016. Pembuatan Aplikasi Mobile Gis Berbasis Android Untuk Informasi Pariwisata Di Kabupaten Gunungkidul. Jurnal Geodesi Undip April 2015, Volume, Nomor, Tahun 2015, (ISSN : 2337-84.

[2] Aini, A. 2012. Sistem Informasi Geografis. Yogyakarta: STIMIK AMIKOM Yogyakarta.

[3] Suprianto, D., \& Agustin, R. 2012. Pemrograman Aplikasi Android. Yogyakarta: MediaKom.

[4] Sucita, Agus, 2012 "Pembangunan Sistem Aplikasi Layanan Berbasis Lokasi Pencarian ATM dan POM Bensin Terdekat Berbasis Android”, STMIK AMIKOM, Yogyakarta.

[5] Elian. 2012. Layanan informasi Google maps. Semarang

[6] Safaat. (2012). Pemrograman Aplikasi Mobile Smartphone dan Tablet PC. Bandung: Informatika Bandung.

[7] Kasiman, P. 2006. Aplikasi Web dengan PHP dan MySQL,. Yogyakarta: Andi Offset.

[8] Rosa, A., \& Shalahuddin, M. 2013. Rekayasa Perangkat Lunak. Bandung: Informatika Bandung

[9] Pressman, R. 2012. Software Engineering: A Practitioner's Approach Seventh Edition. New York: McGraw Hill

[10] Sadeli, Muhammad, 2014. Toko Buku Online dengan Android. Palembang, Indonesia: Maxikom

[11] Santoso, K. Imam, Rais, M. Nur, 2015. Implementasi Sistem Informasi Geografis Daerah Pariwisata Kabupaten Temanggung Berbasis Android dengan Global Positioning. 